\title{
Evaluation of Fuji Apple Peel Extract as a Corrosion Inhibitor for Carbon Steel in a Saline Medium
}

\author{
Rosa Vera ${ }^{*}$, Francisco Figueredo, Andrés Díaz-Gómez, Aurora Molinari \\ Institute of Chemistry, Faculty of Sciences, Pontificia Universidad Católica de Valparaíso, \\ Avenida Universidad 330, Placilla (Curauma), Valparaíso, Chile \\ *E-mail: rosa.vera@pucv.cl
}

doi: $10.20964 / 2018.05 .57$

Received: 3 January 2018 / Accepted: 23 February 2018 / Published: 10 April 2018

The present study evaluated the activity of extract obtained from the peel of Fuji apples (Malus Domestica) harvested in the region of Valparaiso, Chile, as a potential corrosion inhibitor for carbon steel in a saline medium. The total phenol and flavonoid content in the extract was measured and its main components were identified using HPLC-MS. The inhibition efficiency of the extract was evaluated by mass loss measurements, Tafel polarisation curves and electrochemical impedance spectroscopy, obtaining an inhibition percentage of around $90 \%$ at a concentration of $1000 \mathrm{ppm}$ of extract. Adsorption of the extract's components on the surface of the steel followed the Langmuir adsorption isotherm model, implying a physisorption mechanism based on thermodynamic parameters and from the $\Delta \mathrm{G}_{\text {ads }}^{0}$ value, which was calculated at $-15.16 \mathrm{KJ} / \mathrm{mol}$. SEM was used to verify the presence of an organic layer on the steel, corroborating the adsorption of the organic components from the extract blocking active sites on the steel.

Keywords: carbon steel, Fuji apple, chloride inhibition, adsorption

\section{FULL TEXT}

(C) 2018 The Authors. Published by ESG (www.electrochemsci.org). This article is an open access article distributed under the terms and conditions of the Creative Commons Attribution license (http://creativecommons.org/licenses/by/4.0/). 